\title{
Preparation of Polymer Electrolyte Membrane with Nanomatrix Channel through Sulfonation of Natural Rubber Grafted with Polystyrene
}

\author{
Lina Fukuhara $^{1)}$, Noriyuki Kado ${ }^{2)}$, Kenichiro Kosugi ${ }^{2)}$, Patjaree Suksawad ${ }^{2)}$, Yoshimasa Yamamoto ${ }^{1)}$, \\ ${\text { Hiroyuki } \text { Ishii }^{1)} \text {, Seiichi Kawahara }}^{2}{ }^{2}$ * \\ 1) Tokyo National College of Technology, Department of Chemical Science and Engineering, \\ 1220-2, Kunugida-cho, Hachioji, Tokyo 193-0997, Japan \\ 2) Nagaoka University of Technology, Department of Materials Science and Technology, \\ 1603-1, Kamitomioka-cho, Nagaoka, Niigata 940-2188, Japan \\ * Nagaoka University of Technology, Department of Materials Science and Technology, \\ 1603-1, Kamitomioka-cho, Nagaoka, Niigata 940-2188, Japan \\ TEL: +81-258-47-9333, FAX: +81-258-47-9333 \\ e-mail: kawahara@mst.nagaokaut.ac.jp
}

\begin{abstract}
Mechanism of proton-transport of a polymer electrolyte membrane (PEM) with nanomatrix channel was investigated with respect to the activation energy of proton conductivity. The PEM with nanomatrix channel was prepared by graft-copolymerization of styrene onto deproteinized natural rubber (DPNR) followed by sulfonation with chlorosulfonic acid. The resulting sulfonated graft-copolymer (SDPNR-graft-PS) was characterized by FT-IR spectroscopy, solid state ${ }^{13} \mathrm{C}$ CP/MAS NMR spectroscopy, elemental analysis, transmission electron microscopy (TEM) and impedance analysis. The PEM was found to form completely continuous nanomatrix channel consisting of natural rubber particle of about $1 \mu \mathrm{m}$ in average diameter as a dispersoid and sulfonated polystyrene of about $60 \mathrm{~nm}$ in thickness as a matrix. The value of the activation energy of proton conductivity estimated from the slope of Arrhenius plot was $12 \mathrm{~kJ} / \mathrm{mol}$ for SDPNR-graft-PS, suggesting that the proton-transport occurred in a manner of Grotthuss mechanism.
\end{abstract}

Key word: Nanomatrix channel, Graft-copolymerization, Natural rubber, Polymer electrolyte membrane 


\section{Introduction}

Mechanism of proton-transport is widely recognized to be indispensable to understand the role of polymer electrolyte membrane (PEM) in fuel cell, which is useful to design a novel PEM as a factor. For instance, the mechanism of the proton-transport for perfluorosulfonic acid is classified into two categories: that is, Grotthuss mechanism and Vehicle mechanism, in which the protons are transported by connecting ion cluster of 20 to $30 \mathrm{~nm}$ in diameter through a channel of several $\mathrm{nm}$ in thickness [1]. The difference in the proton-transport between the two mechanisms are schematically illustrated in Fig. 1. In the Vehicle mechanism, the protons are transported by diffusing into water as hydrated proton aggregates. In the Grotthuss mechanism, in contrast, the protons are transported by jumping from one sulfonic acid to the other through aqueous environment, in which an effective proton concentration may be an important factor for the proton-transport. It is, therefore, quite important to investigate the relationship between proton conductivity and temperature, since the effective proton concentration of PEM may be estimated from Arrhenius plot.

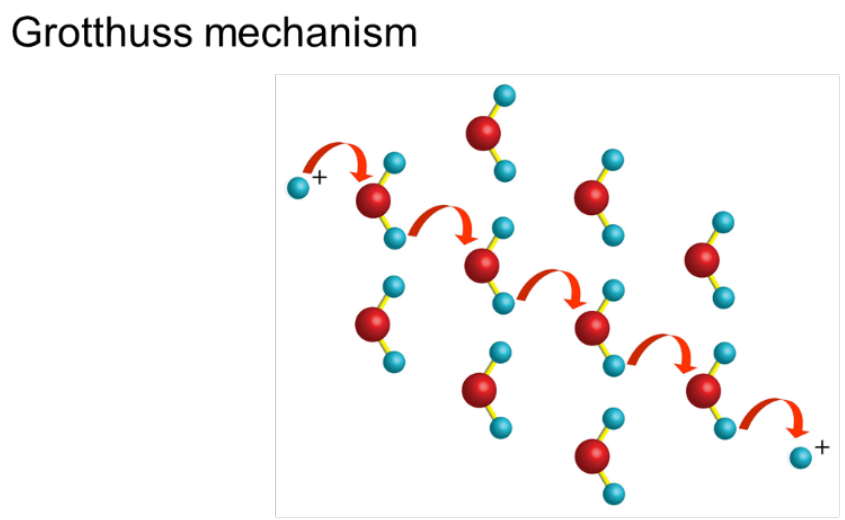

vehicle mechanism

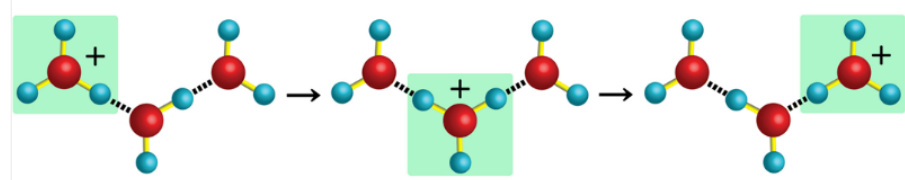

Fig. 1 Schematic illustration of proton-transport in PEM

In our previous works [2,3], nanomatrix channel was proposed to be the novel nano-phase separated structure for the effective proton-transport, which consisted of particles of hydrophobic polymer of about $1 \mu \mathrm{m}$ in diameter covered with a nano-layers of hydrophilic polymer. It possessed infinite paths of nano-channel to transport the protons, which was useful for the PEM. The nanomatrix channel was formed by graft-copolymerization of styrene onto surface of natural rubber particles in latex stage followed by sulfonation with chlorosulfonic acid, as shown in Fig. 2. A proton conductivity of the resulting PEM (SDPNR-graft-PS) was higher than that of sulfonated polystyrene and perfluorosulfonic acid membranes. However, we have not investigated the mechanism of the proton-transport of SDPNR-graft-PS.

Many studies on the proton-transport of the PEM have been performed with sulfonic acid containing membranes [4-8]. Yeo and co-workers [9] reported that the proton conductivity of the PEM increased with increasing temperature and it was dependent upon water content on the basis of the ion cluster model. Moreover, 
Zhong and co-workers estimated an activation energy of the PEM to investigate a mechanism of the proton-transport: that is, $14-40 \mathrm{~kJ} / \mathrm{mol}$ for Grotthuss mechanism and more than $40 \mathrm{~kJ} / \mathrm{mol}$ for vehicle mechanism [10]. Therefore, it is possible to investigate the mechanism of the proton-transport of PEM with nanomatrix channel with respect to the activation energy of the proton conductivity.

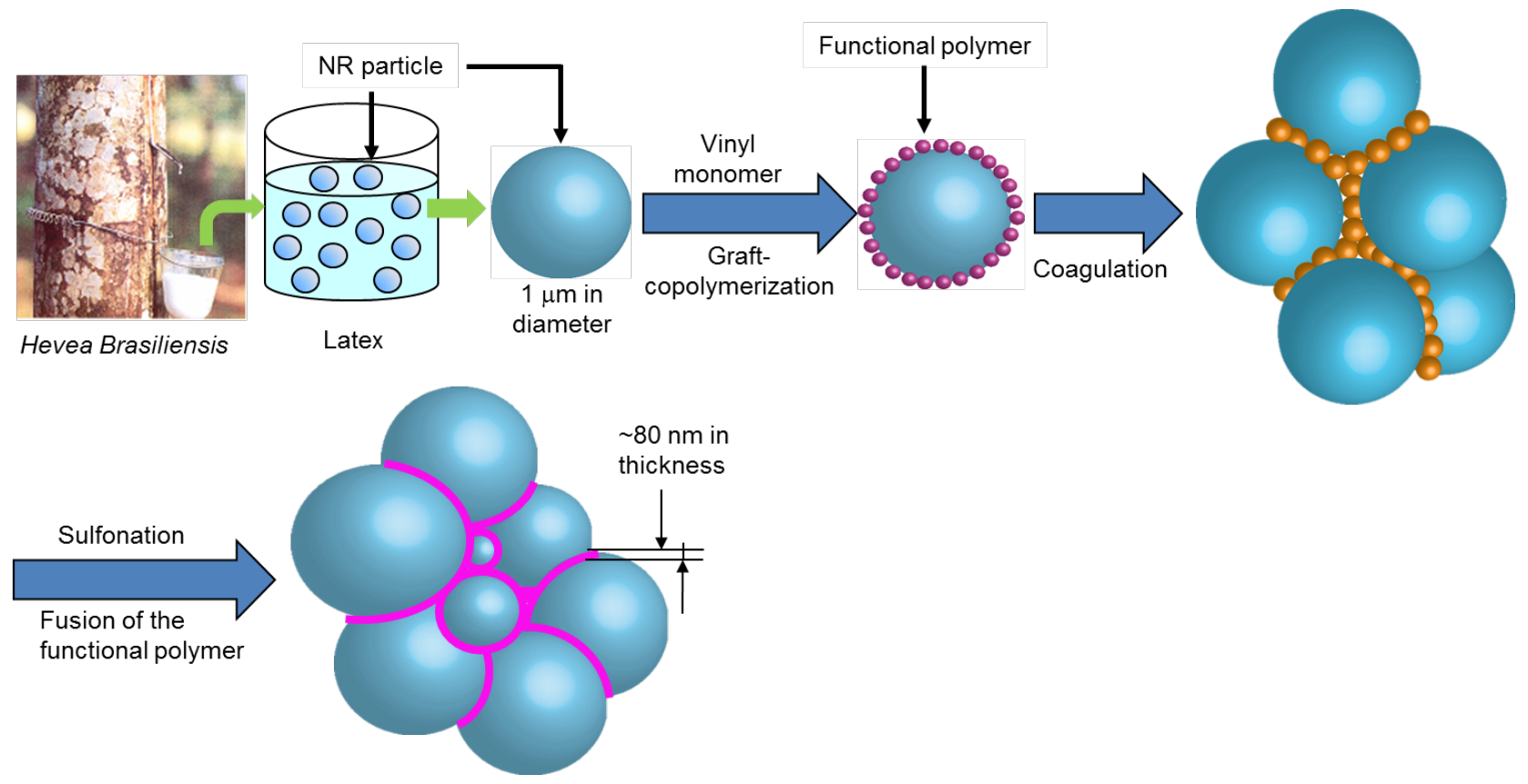

Fig. 2 Preparation of PEM with nanomatrix channel from natural rubber

In the present study, condition of graft-copolymerization of styrene onto deproteinized natural rubber (DPNR) in latex stage was optimized to prepare DPNR-graft-PS. The resulting DPNR-graft-PS was sulfonated with chlorosulfonic acid to prepare a PEM with nanomatrix channel. The resulting sulfonated graft-copolymer (SDPNR-graft-PS) was characterized by FT-IR spectroscopy, solid state ${ }^{13} \mathrm{C}$ CP/MAS NMR spectroscopy, elemental analysis, transmission electron microscopy (TEM) and impedance analyzer. The proton conductivity was analyzed as a function of temperature.

\section{Experimental}

\section{Materials}

Natural rubber latex used in the present study was commercial high-ammonia natural rubber (HA-NR) latex (Golden Hope, Malaysia) of about 60\% dry rubber content (DRC). Sodium dodecyl sulfate (SDS: 98\%), tert-butylhydroperoxide (TBHP) and tetraethylenepentamine (TEPA) were purchased from Kishida Chemical Co., Ltd. Chloroform- $d$ (99.8\%), chloroform (99\%) and chlorosulfonic acid (97\%) were purchased from Wako Pure Chemical Industry Ltd. Styrene monomer (99\%) was purchased from Tokyo Chemical Industry Co., Ltd. Methanol (99.5\%), toluene (99.5\%), sodium hydroxide ( $\mathrm{NaOH}$ : 97\%), urea (99.5\%) were purchased from Nacalai tesque Inc. Ruthenium tetroxide $\left(\mathrm{RuO}_{4}\right)$ was prepared by oxidation of ruthenium (III) chloride hydrate $\left(\mathrm{RuCl}_{3} \cdot \mathrm{H}_{2} \mathrm{O}\right)$ with sodium hypochlorite solution (NaClO) purchased from Aldrich and Nacalai tesque Inc., respectively. 


\section{Preparation of DPNR}

Deproteinization of natural rubber was performed by incubation of natural rubber latex with $0.1 \mathrm{wt} \%$ urea in the presence of $1 \mathrm{wt} \%$ SDS at room temperature for $1 \mathrm{~h}$ followed by centrifugation at $10^{4} \mathrm{rpm}$. The cream fraction after centrifugation was re-dispersed in $0.5 \mathrm{wt} \%$ SDS solution to make $30 \mathrm{wt} \%$ DRC latex and it was washed twice by centrifugation to prepare DPNR latex. The DRC of DPNR latex was adjusted to 30 wt\% with distilled water and SDS was added up to $0.1 \mathrm{wt} \%$.

\section{Preparation of DPNR-graft-PS}

Graft-copolymerization of DPNR latex was carried out with styrene as a monomer, using TBHP/ TEPA as an initiator. DPNR latex was charged with $\mathrm{N}_{2}$ gas for an hour at $30{ }^{\circ} \mathrm{C} .3 .3 \times 10^{-2} \mathrm{~mol} / \mathrm{kg}$-rubber of initiator and $1.5 \mathrm{~mol} / \mathrm{kg}$-rubber of monomer were added in turn to the latex, respectively. The reaction was carried out by stirring the latex at about $400 \mathrm{rpm}$ for $5 \mathrm{~h}$ at $30^{\circ} \mathrm{C}$. The un-reacted styrene was removed by using a rotary evaporator under reduced pressure. The as-cast film of the DPNR-graft-PS was prepared by casting the gross polymer latex into a Petri-dish and it was dried under reduced pressure at ambient temperature for more than a week. The gross polymer was extracted with acetone/2-butanone 3:1 mixture in a Soxhlet apparatus under nitrogen atmosphere in the dark and dried under reduced pressure for a week, in which the removal of almost all free-polystyrene, isolated from natural rubber, was completed by the extraction for $24 \mathrm{~h}$.

\section{Preparation of SDPNR-graft-PS}

Sulfonation of DPNR-graft-PS was performed by the following procedure. The DPNR-graft-PS film was immersed in chloroform for 5 min until swollen. The sulfonation of the DPNR-graft-PS was carried out with a solution of $0.8 \mathrm{~N}$ chlorosulfonic acid in chloroform at $30^{\circ} \mathrm{C}$ for $5 \mathrm{~h}$. After completion of the sulfonation, the resulting membrane was immersed into methanol for $30 \mathrm{~min}$, followed by washed several times with ion-exchange water until water was neutral. The resulting SDPNR-graft-PS was dried under reduced pressure at $50{ }^{\circ} \mathrm{C}$. Prior to characterizations of the SDPNR-graft-PS, the membranes were acidified with $0.5 \mathrm{~mol} / \mathrm{L} \mathrm{H}_{2} \mathrm{SO}_{4}$ solution at $80^{\circ} \mathrm{C}$ for $1 \mathrm{~h}$ and rinsed with water. Then, they were boiled with ion exchange water at $80^{\circ} \mathrm{C}$ for $1 \mathrm{~h}$, twice, followed by dried under reduced pressure at $50^{\circ} \mathrm{C}$ for a week.

\section{Characterization}

NMR measurements were carried out using a JEOL ECA-400 spectrometer operating at 399.65 and 100.4 MHz for ${ }^{1} \mathrm{H}$ and ${ }^{13} \mathrm{C}$, respectively. For a solution state ${ }^{1} \mathrm{H}$ NMR measurement, the rubber was dissolved into chloroform- $d$. Chemical shifts were referred to TMS. Solid state CP/MAS NMR measurement was carried out at room temperature with spin rate of $7 \mathrm{kHz}$, scan time of 1000 scans, and contact time of $5 \mathrm{sec}$, respectively. Hexamethylbenzene was used as an external standard (17.3 ppm). The samples were crushed by JFC-300 cryogenic sample crusher before the measurement.

Sulfur content of the samples was determined by elemental analysis (YANACO MT-6 and MSU-32 microanalyzers).

Water uptake of the samples was measured by the following method. The membranes were soaked in water at room temperature for a week to reach the saturated point of the membrane. Water-droplets on the surface of swollen membranes were removed by wiping with tissue paper. The water uptake was determined from a 
weight of swollen membrane and dry membrane.

Ion exchange capacity (IEC) of the samples was investigated by titration method. The samples were immersed in $2 \mathrm{~N} \mathrm{NaCl}$ solution for a week to replace $\mathrm{H}^{+}$to $\mathrm{Na}^{+}$ions. The $\mathrm{H}^{+}$ions in the solution were titrated with $0.1 \mathrm{~N}$ of $\mathrm{NaOH}$ solution in the present of phenolphthalein as an indicator. The IEC (meq/g) was calculated from the volume of $\mathrm{NaOH}$ solution and weight of dry membrane.

Proton conductivity was measured with a Solartron SI 1260 impedance/gain-phase analyzer and potentiostat (Solartron SI 1287 electrochemical interface) in a range of the frequency between $10 \mathrm{mHz}$ and $10^{6} \mathrm{~Hz}$ at AC voltage amplitude of $10 \mathrm{mV}$. The impedance was measured by placing the cell in a temperature-controlled chamber (ESPEC CORP, SU-222) under a temperature range of $50-80^{\circ} \mathrm{C}$. The membranes were hydrated by immersion in ion-exchange water for $3 \mathrm{~h}$ before measurement.

Observations of morphology for the samples were made with a transmission electron microscope (TEM), JEOL JEM-2100 at accelerating voltage of $200 \mathrm{kV}$. The ultra thin sections for the TEM experiments were prepared with a microtome (Ultracut N, Reichert-Nissei FC S) between -40 and $-90^{\circ} \mathrm{C}$. The thin sections with the thickness of about $100 \mathrm{~nm}$ were stained with $\mathrm{RuO}_{4}$ at room temperature for $1 \mathrm{~min}$.

\section{Results and Discussion}

Fig. 3 shows FT-IR spectra for DPNR, polystyrene (PS) and DPNR-graft-PS prepared with 1.5 $\mathrm{mol} / \mathrm{kg}$-rubber of styrene and $3.3 \times 10^{-2} \mathrm{~mol} / \mathrm{kg}$-rubber of initiator, ranging from $1500 \mathrm{~cm}^{-1}$ to $2000 \mathrm{~cm}^{-1}$. As for DPNR (Fig. 3(A)), two peaks appeared at 1660 and $1740 \mathrm{~cm}^{-1}$, which were identified to stretching vibrations of carbon-carbon double bond of cis-1,4-isoprene units and carbonyl group of fatty acid contained in natural rubber as a non-rubber component, respectively. In contrast, for PS, six peaks appeared at 1580, 1600, 1740, 1800, 1870 and $1950 \mathrm{~cm}^{-1}$, which was identified to phenyl group of styrene units. After graft-copolymerization, peaks appearing in the spectrum for DPNR-graft-PS were, thus, identified to cis-1,4-isoprene units and styrene units. The intensity of the peak at $1600 \mathrm{~cm}^{-1}$ was a little bit smaller than that of the peak at $1660 \mathrm{~cm}^{-1}$. However, we couldn't quantitatively determine the styrene unit content of the DPNR-graft-PS, since it was heterogeneous multi-component system, which possessed PS domains and DPNR domains, individually. Therefore, In order to determine the styrene unit content, the DPNR-graft-PS was subjected to solution state ${ }^{1} \mathrm{H}-\mathrm{NMR}$ spectroscopy.

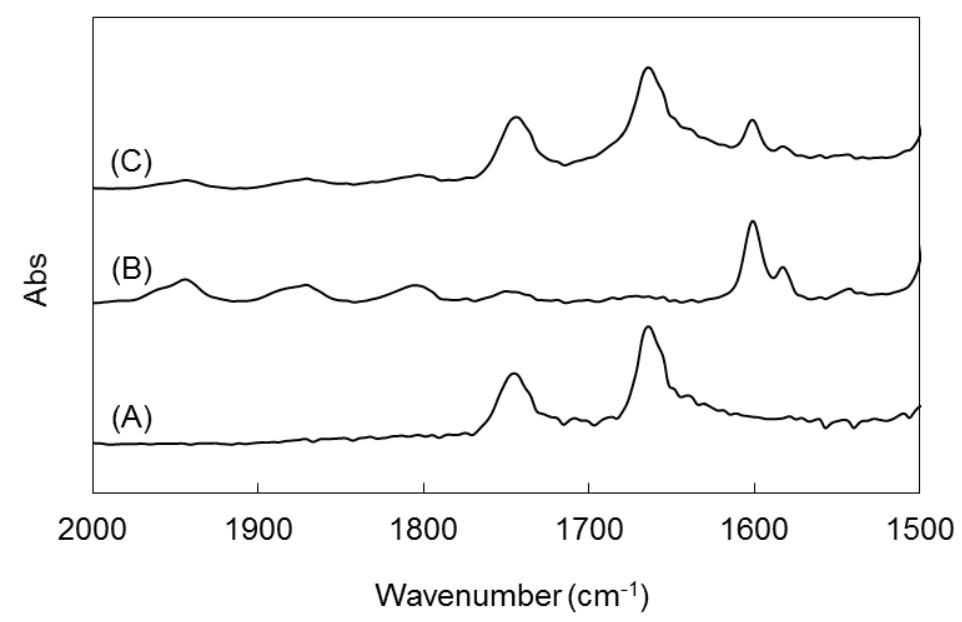

Fig. 3 FT-IR Spectra of (A) DPNR, (B) polystyrene, and (C) DPNR-graft-PS 
Fig. 4 shows solution state ${ }^{1} \mathrm{H}-\mathrm{NMR}$ spectra for DPNR and DPNR-graft-PS prepared with 1.5 $\mathrm{mol} / \mathrm{kg}$-rubber of styrene and $3.3 \times 10^{-2} \mathrm{~mol} / \mathrm{kg}$-rubber of initiator. In the spectrum for DPNR, three signals appeared at 1.8, 2.1 and $5.1 \mathrm{ppm}$, which were assigned to methyl, methylene and unsaturated methine protons of cis-1,4-isoprene units, respectively. After graft-copolymerization of styrene onto DPNR (Fig. 4(B)), two broad signals appeared at 6-7 ppm, which were assigned to phenyl proton of styrene units. The signals of the aliphatic protons of polystyrene were overlapped with that of cis-1,4-isoprene units at 1.8-2.1 ppm. From the intensity of the signals, we estimated styrene unit contents of DPNR-graft-PS and, subsequently, conversion and grafting efficiency of styrene.

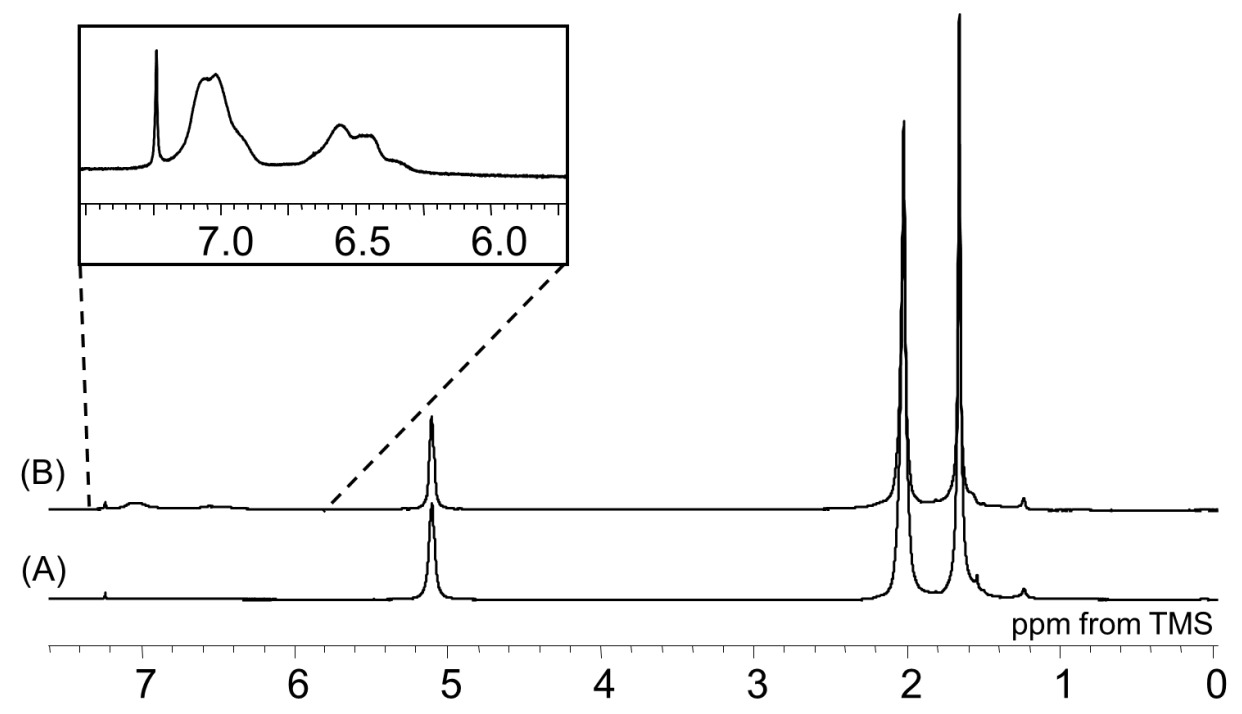

Fig. $4{ }^{1} \mathrm{H}$ NMR spectra of (A) DPNR and (B) DPNR-graft-PS

The conversion of styrene, content of styrene units and grafting efficiency of styrene were estimated, as in the following equations:

$$
\text { Conversion of styrene }(\%)=\frac{\text { Weight of polystyrene in gross polymer }}{\text { Weight of polystyrene used for the graft copolymer }} \times 100
$$

$$
\text { Content of styrene }(\%)=\frac{\text { Weight of polystyrene in gross polymer }}{\text { Weight of gross polymer }} \times 100
$$

$$
\text { Grafting efficiency }(\%)=\frac{\text { Mole of polystyrene linking to natural rubber }}{\text { Mole of polystyrene produced during graft copolymerization }} \times 100
$$

where mole of polystyrene in gross polymer, mole of gross polymer and mole of monomer were estimated from intensity ratios of the signals appearing in the NMR spectra and weights of specimen determined by gravimetric method. Table 1 shows conversion and grafting efficiency of styrene, and styrene unit content, respectively. The conversion and grafting efficiency of styrene were dependent upon the feeds of initiator and styrene; for instance, a maximum value of the conversion, i.e. $91 \%$, was accomplished at $1.5 \mathrm{~mol} / \mathrm{kg}$-rubber of styrene and $3.3 \times 10^{-2} \mathrm{~mol} / \mathrm{kg}$-rubber 
of the initiator. In contrast, the styrene unit content of DPNR-graft-PS increased with increasing the feed of styrene. The styrene unit content was the highest, i.e. $12 \%$, at $1.5 \mathrm{~mol} / \mathrm{kg}$-rubber of styrene and $3.3 \times 10^{-2}$ $\mathrm{mol} / \mathrm{kg}$-rubber of the initiator. This may be explained to be due to deactivation and chain transformation of the radicals, which may come from less and large amount of styrene, respectively. These results indicate that suitable feeds of initiator and styrene for the graft-copolymerization are $3.3 \times 10^{-2} \mathrm{~mol} / \mathrm{kg}$-rubber and $1.5 \mathrm{~mol} / \mathrm{kg}$-rubber, respectively.

Table 1 Conversion, content and grafting-efficiency in the graft-copolymerization

\begin{tabular}{ccccc}
\hline $\begin{array}{c}\text { Feed of Styrene } \\
\text { (mol/kg-rubber) }\end{array}$ & $\begin{array}{c}\text { Feed of Initiator } \\
\text { (mol/kg-rubber) }\end{array}$ & $\begin{array}{c}\text { Conversion of } \\
\text { styrene (\%) }\end{array}$ & $\begin{array}{c}\text { Grafting } \\
\text { efficiency of } \\
\text { styrene (\%) }\end{array}$ & $\begin{array}{c}\text { Styrene unit } \\
\text { content (\%) }\end{array}$ \\
\hline 1.5 & $1.0 \times 10^{-2}$ & 42 & 68 & 6 \\
1.5 & $1.7 \times 10^{-2}$ & 47 & 65 & 6 \\
1.5 & $3.3 \times 10^{-2}$ & 91 & 91 & 12 \\
1.5 & $6.6 \times 10^{-2}$ & 77 & 59 & 10 \\
0.5 & $3.3 \times 10^{-2}$ & 4 & 1 & 1 \\
2.0 & $3.3 \times 10^{-2}$ & 82 & 77 & 15 \\
2.5 & $3.3 \times 10^{-2}$ & 66 & 75 & 15 \\
\hline
\end{tabular}

Fig. 5 shows TEM images for DPNR-graft-PS prepared with $1.5 \mathrm{~mol} / \mathrm{kg}$-rubber of styrene and $3.3 \times 10^{-2}$ $\mathrm{mol} / \mathrm{kg}$-rubber of initiator. The bright domains represent polystyrene and the gloomy domains represent natural rubber, since DPNR-graft-PS was stained with $\mathrm{OsO}_{4}$ [11]. Natural rubber particles of about $1 \mu \mathrm{m}$ in average diameter were well dispersed in the PS nanomatrix of about $30 \mathrm{~nm}$ in thickness, which consisted of PS nano-particles of about $5 \mathrm{~nm}$ in diameter to form a discontinuous nanomatrix, as reported in our previous work [12]. This implies that the matrix is less useful for proton conductivity, because of the discontinuity. Consequently, the DPNR-graft-PS was found to be a precursor to prepare the PEM with nanomatrix channel. It is necessary to form continuous nanomatrix and convert PS to a proton conductive medium.

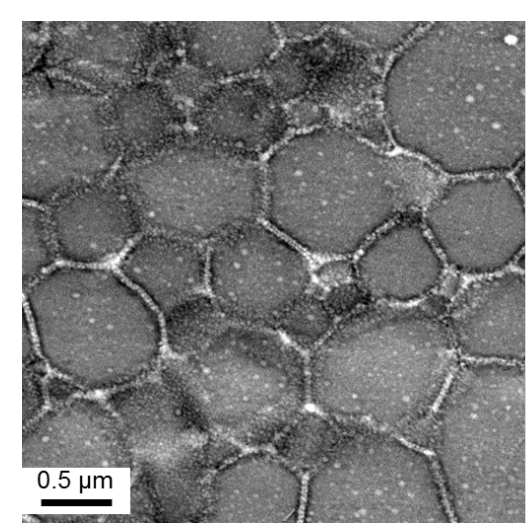

(A)

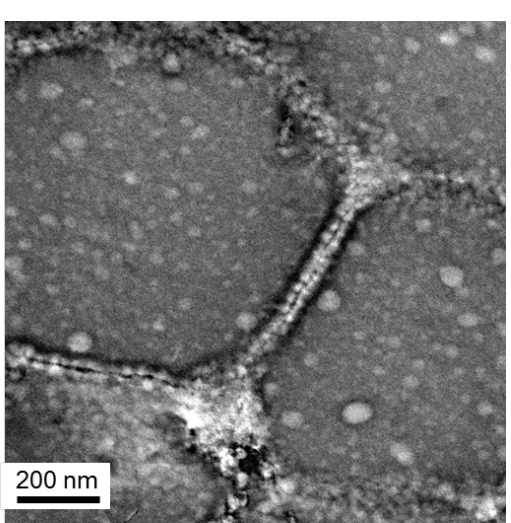

(B)

Fig. 5 TEM images of DPNR-graft-PS: (A) x5000, (B) x20000 
The resulting DPNR-graft-PS prepared was sulfonated with chlorosulfonic acid. Fig. 6 shows FT-IR spectra for DPNR-graft-PS, SDPNR-graft-PS and sulfonated DPNR (SDPNR). Peak height of the spectrum was normalized in comparison with a height of reference peak at $1660 \mathrm{~cm}^{-1}$ identified as the stretching vibration of the carbon-carbon double bond of cis-1,4-isoprene unit. It was found that the absorbance peaks at $3400 \mathrm{~cm}^{-1}, 1164$ $\mathrm{cm}^{-1}$ and $1038 \mathrm{~cm}^{-1}$ appeared in the spectra of SDPNR-graft-PS (Fig. 6(B)) and sulfonated DPNR (Fig. 6(C)) whereas they did not appear in the spectrum of DPNR-graft-PS (Fig. 6(A)). The absorbance peaks at $3400 \mathrm{~cm}^{-1}$, $1164 \mathrm{~cm}^{-1}$ and $1038 \mathrm{~cm}^{-1}$ were identified to $\mathrm{OH}$ stretching vibration, $\mathrm{S}=\mathrm{O}$ asymmetric stretching vibration and $\mathrm{S}=\mathrm{O}$ symmetric stretching vibration of the sulfonic acid group, respectively. Furthermore, the peak at $1009 \mathrm{~cm}^{-1}$ was identified to the in-plane bending vibration of a para-substituted aromatic ring of the sulfonated polystyrene [13]. These results suggested that the sulfonic acid groups were incorporated into not only styrene units of DPNR-graft-PS but also natural rubber, after sulfonation of DPNR-graft-PS with chlorosulfonic acid.
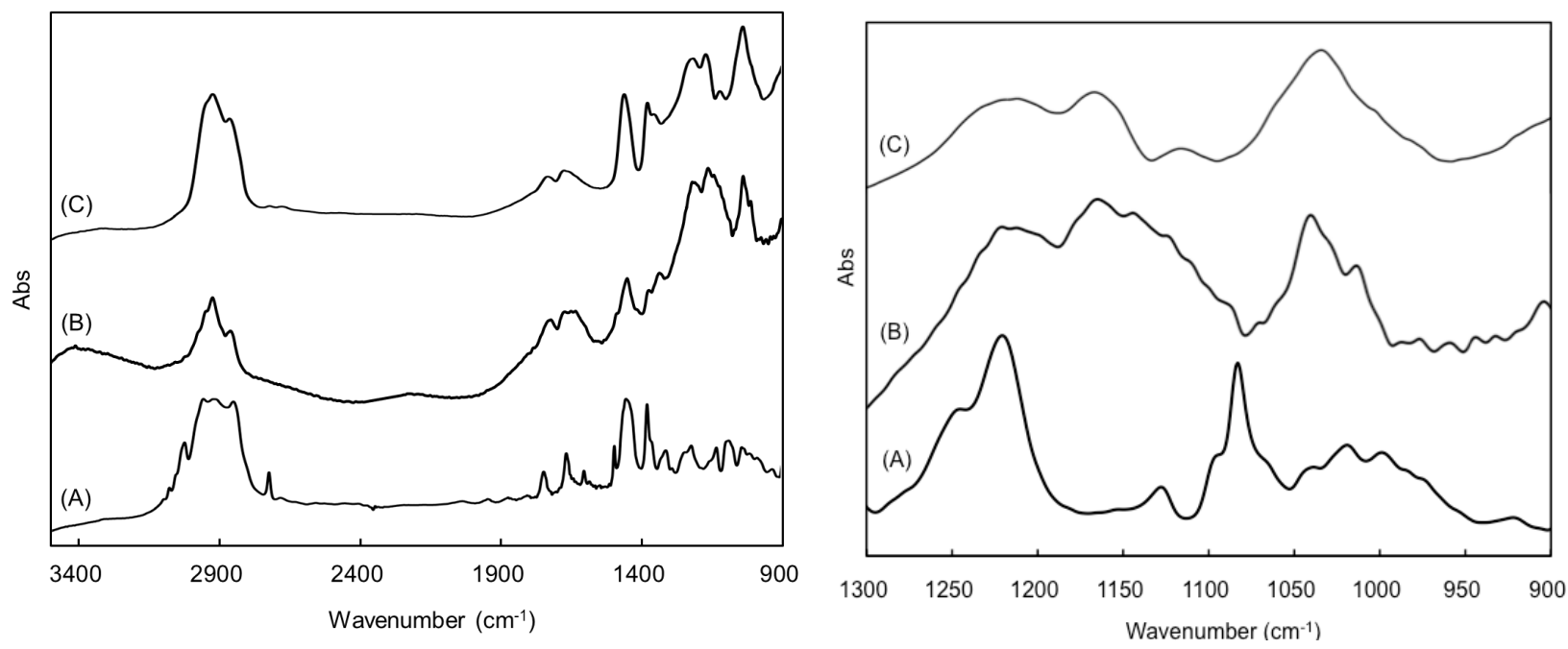

Fig. 6 FT-IR spectra for (A) DPNR-graft-PS, (B) SDPNR-graft-PS and (C) sulfonated DPNR

Fig. 7 shows the ${ }^{13} \mathrm{C}$ CP/MAS NMR spectra for DPNR-graft-PS, SDPNR-graft-PS, and sulfonated DPNR. In the spectrum of DPNR-graft-PS, five signals appeared at 24, 27, 33, 126 and $136 \mathrm{ppm}$, which were assigned to methyl, methylene, methylene, methine and quaternary carbons of cis-1,4-isoprene units, respectively (Fig. 7 (A)). Furthermore, signals at 41 and 147 ppm were assigned to methylene carbon and aromatic carbons of the styrene units, respectively. After sulfonation of DPNR-graft-PS (Fig. 7(B)), new broad signals appeared at 120-150 ppm, which overlapped with the signals of olefinic carbon of cis-1,4-isoprene units and aromatic carbons of styrene units. In contrast, very broad signals appeared in the aliphatic region ranging from $10 \mathrm{ppm}$ to $80 \mathrm{ppm}$. They also overlapped with many signals in the spectrum. The signals shown in Fig. 7(B) were assigned by comparison with that of sulfonated DPNR as a model compound. In the spectrum of sulfonated DPNR (Fig. 7(C)), two overlapping broad signals appeared at 10-80 ppm and 110-155 ppm, respectively. The broad signals appeared due to the presence of complicated structural units in the polymer after sulfonation of the DPNR. According to a previous study, the overlapping broad signals in the aliphatic region ranging from $10 \mathrm{ppm}$ to $80 \mathrm{ppm}$ were assigned to methyl and methylene carbons of cyclized cis-1,4-isoprene units, and that in the olefinic region ranging from 110 ppm to 155 ppm were assigned to the olefinic methine and trisubstituted carbons [14]. Thus, the broad signals in 
the ${ }^{13} \mathrm{C}$ CP/MAS NMR spectrum for the SDPNR-graft-PS were assigned to the cyclized cis-1,4-isoprene units and the sulfonated PS units.

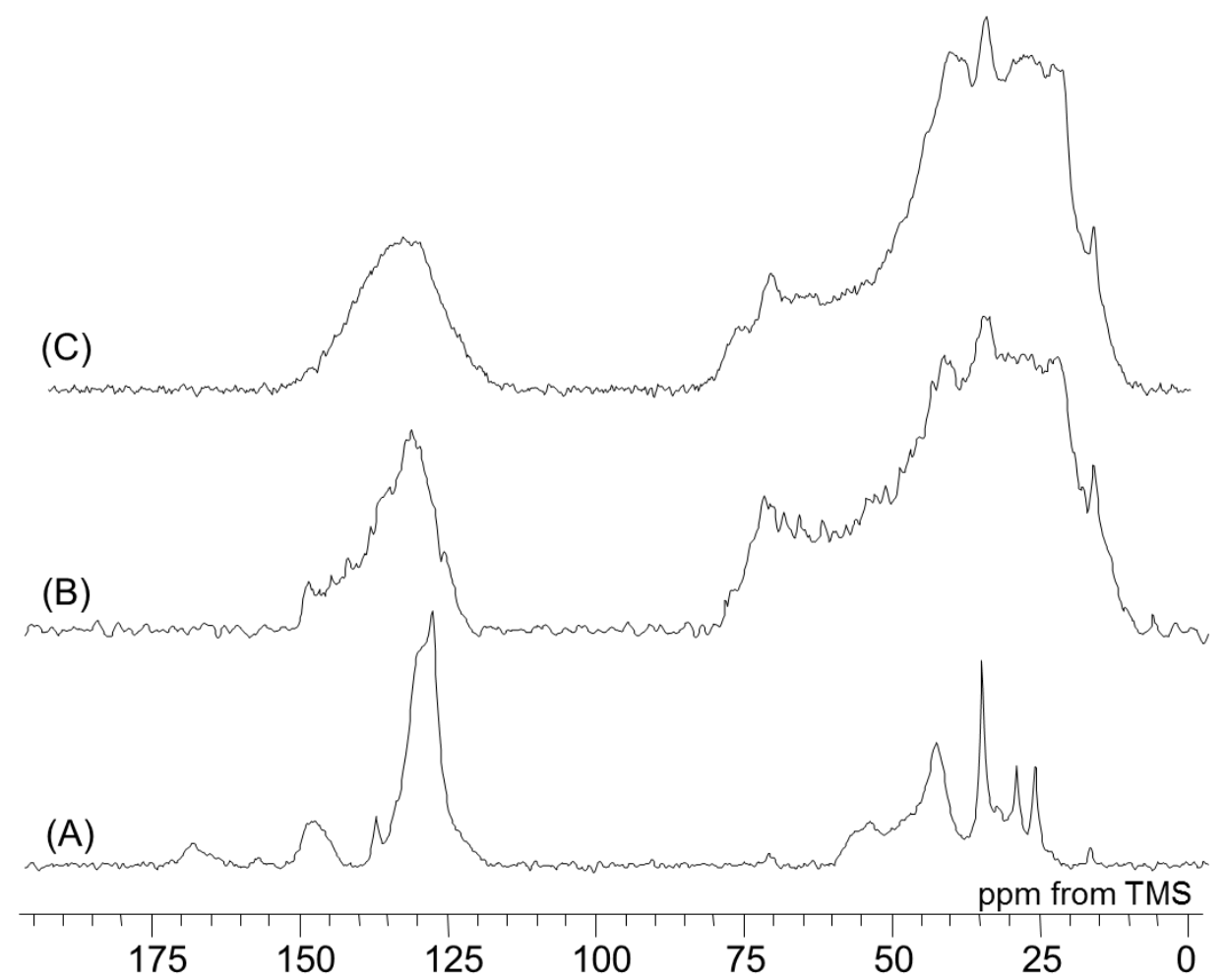

Fig. $7{ }^{13} \mathrm{C}$ CP/MAS NMR spectra for (A) DPNR-graft-PS, (B) SDPNR-graft-PS, and (C) SDPNR

Fig. 8 shows TEM images for SDPNR-graft-PS, which was prepared with a chloroform solution of $0.8 \mathrm{~N}$ chlorosulfonic acid. The bright domains represent natural rubber and the gloomy domains represent sulfonated PS, since the film specimen was stained with $\mathrm{RuO}_{4}$. The dark sulfonated PS domains was found to form continuous nanomatrix, i.e. the nanomatrix channel, the thickness of which was about $60 \mathrm{~nm}$. On the other hand, the bright natural rubber domains, which contained cyclized natural rubber, were dispersed in the nanomatrix. These demonstrate that the continuous nanomatrix channel is formed in chloroform solution without destroying the nanomatrix structure. This may be explained to be due to the difference in the molecular weight between natural rubber and PS. In the previous work, we reported that the weight average molecular weight of PS of DPNR-graft-PS was about 15 thousand, which was significantly lower than that of natural rubber, i.e. about 2 million. In this case, lower molecular weight PS may be easily dissolved into chloroform, whereas higher molecular weight natural rubber may not. Thus, the PS nano-particles may be dissolved in to chloroform to form the continuous nanomatrix and, then, PS may react with chlorosulfonic acid. During this reaction, natural rubber particles may keep their shapes. The continuous nanomatrix channel, thus formed, may be useful to transport protons as a PEM. 

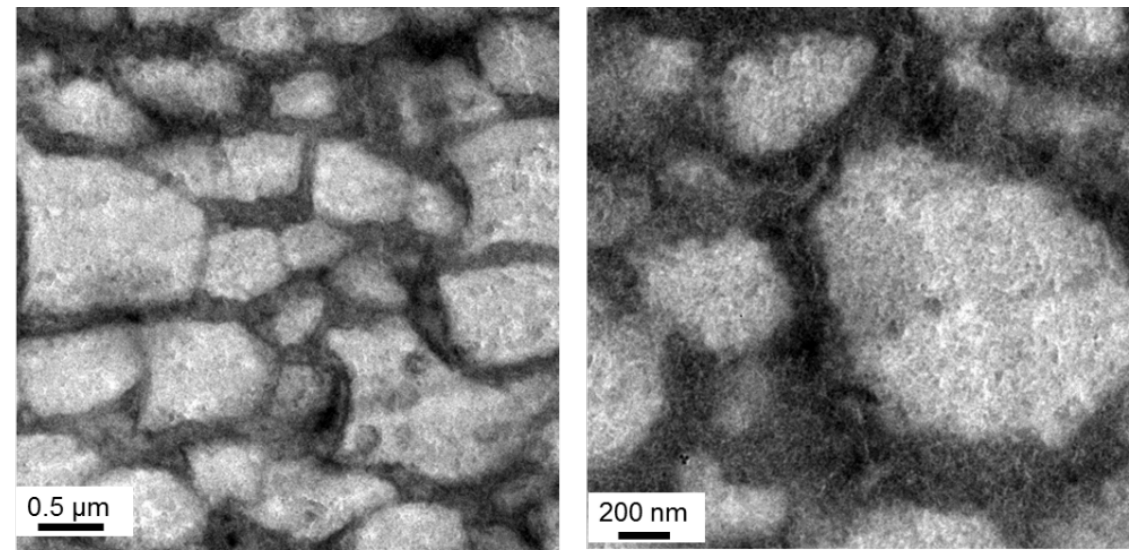

Fig. 8 TEM images of SDPNR-graft-PS: (A) x5000, (B) x20000

Table 2 shows the sulfur content, proton conductivity, ion exchange capacity (IEC), and water uptake of DPNR, sulfonated DPNR, DPNR-graft-PS, SDPNR-graft-PS, and Nafion $117^{\circledR}$. The sulfur content was estimated, as in the following equation:

$$
\text { Sulfur content }(\mathrm{wt} \%)=\frac{\text { Weight of sulfur }}{\text { Weight of sample }} \times 100
$$

where weight of sulfur was determined from the results of an elemental analysis. The sulfur content of the sulfonated DPNR was $5.8 \mathrm{w} / \mathrm{w} \%$ because the sulfonic acid group was incorporated into the DPNR, as shown in Figure 6(C). In contrast, the sulfur content of the SDPNR-graft-PS was $10.2 \mathrm{w} / \mathrm{w} \%$, which was twice as high as that of sulfonated DPNR. This may be explained to be due that nucleophilic sulfonation proceeded preferentially on the benzene ring of the polystyrene. On the other hand, a degree of sulfonation estimated from sulfur content was 276 mol\%, suggesting that sulfonic acid group was incorporated into not only benzene ring of polystyrene but also natural rubber.

$$
\text { Degree of sulfonation }(\mathrm{mol} \%)=\frac{\text { mol of sulfur }}{\text { mol of styrene unit }} \times 100
$$

The IEC of the rubbers was investigated by titration method, in which the calculation was shown in the following equation:

$$
\operatorname{IEC}(\mathrm{wt} \%)=\frac{N_{\mathrm{NaOH}} \times V_{\mathrm{NaOH}}}{W_{\mathrm{dry}}} \times 100
$$

where $\mathrm{N}_{\mathrm{NaOH}}, \mathrm{V}_{\mathrm{NaOH}}$, and $\mathrm{W}_{\text {dry }}$ are the normality of $\mathrm{NaOH}$, the volume of $\mathrm{NaOH}$ solution consumed in the titration, and the weight of dry membrane (g), respectively. The values of IEC of sulfonated DPNR and SDPNR-graft-PS were $1.15 \mathrm{meq} / \mathrm{g}$ and $1.44 \mathrm{meq} / \mathrm{g}$, whereas those of DPNR and DPNR-graft-PS were $0.00 \mathrm{meq} / \mathrm{g}$. This may be attributed to the effect of the incorporated sulfonic acid groups of the rubber on the IEC.

The proton conductivity of the rubbers was calculated as follows:

$$
\text { Proton conductivity }(\mathrm{S} / \mathrm{cm})=\frac{d}{R \times A} \times 100
$$


where $\mathrm{d}$ is the sample thickness, $\mathrm{R}$ is the membrane resistance, and $\mathrm{A}$ is surface area of the membranes. The proton conductivity of DPNR was $0 \mathrm{~S} / \mathrm{cm}$ due to the absence of sulfonic acid group in the DPNR. In contrast, that of sulfonated DPNR was $1.1 \times 10^{-2} \mathrm{~S} / \mathrm{cm}$. This may reflect to an incorporation of sulfonic acid group into DPNR. It is worthy of note that the proton conductivity of SDPNR-graft-PS was $9.8 \times 10^{-2} \mathrm{~S} / \mathrm{cm}$, which was significantly higher than that of Nafion $117^{\circledR}\left(8.0 \times 10^{-2} \mathrm{~S} / \mathrm{cm}\right)$ and sulfonated DPNR $\left(1.1 \times 10^{-2} \mathrm{~S} / \mathrm{cm}\right)$. This was attributed to an increase in the sulfur content and to the formation of continuous nanomatrix channel, as shown in Fig. 8.

The water uptake of the rubbers was calculated through the following equation:

$$
\text { Water uptake }(\mathrm{wt} \%)=\frac{W_{\text {wet }} \times W_{\text {dry }}}{W_{\text {dry }}} \times 100
$$

where $W_{\text {wet }}$ is the weight of swollen membrane and $W_{\text {dry }}$ is the weight of the dry membrane. The water uptake of SDPNR-graft-PS was $66.5 \mathrm{wt} \%$, which was similar to that of sulfonated DPNR. This is significantly distinguished from the water uptake of sulfonated PS, i.e. $340.0 \mathrm{wt} \%$, even though the IEC of sulfonated PDNR-graft-PS was similar to that of sulfonated PS. The chemical linkages between sulfonated PS and DPNR may prevent swelling DPNR-graft-PS with water to reduce the water uptake.

Consequently, the nanomatrix channel was found to play an important role in high proton conductivity and low water uptake.

Table 2 Sulfur content, proton conductivity, ion exchange capacity (IEC), and water uptake of DPNR, SDPNR, DPNR-graft-PS, SDPNR-graft-PS, and Nafion $117^{\circledR}$

\begin{tabular}{ccccc}
\hline Specimen & $\begin{array}{c}\text { Sulfur content } \\
(\mathrm{wt} \%)\end{array}$ & $\begin{array}{c}\text { Conductivity }^{\text {a) }} \\
(\mathrm{S} / \mathrm{cm})\end{array}$ & $\begin{array}{c}\text { IEC } \\
(\mathrm{meq} / \mathrm{g})\end{array}$ & $\begin{array}{c}\text { Water uptake } \\
(\mathrm{wt} \%)\end{array}$ \\
\hline DPNR & - & 0.0 & 0.00 & - \\
SDPNR & 5.8 & 0.011 & 1.15 & 51.2 \\
DPNR-graft-PS & - & 0.0 & 0.00 & - \\
SDPNR-graft-PS & 10.2 & 0.29 & 1.44 & 66.5 \\
Sulfonated PS & - & 0.032 & 1.50 & 340.0 \\
Nafion117 & - & 0.055 & 1.02 & 18.6 \\
\hline
\end{tabular}

a) measured at $50^{\circ} \mathrm{C}$

Fig. 9 shows Arrhenius plot for proton conductivity, $\sigma$, of SDPNR-graft-PS and Nafion $117^{\circledR}$. The proton conductivity of SDPNR-graft-PS and Nafion $117^{\circledR}$ increased with increasing temperature. The apparent activation energy of SDPNR-graft-PS and Nafion $117^{\circledR}$ was estimated from the slope of the plot, as in the following expression:

$$
\begin{aligned}
\sigma(T) & =\sigma_{0} \exp \left[-B /\left(T-T_{0}\right)\right] \times 100 \\
& =\mathrm{A} T^{-1 / 2} \exp \left[-B / T-T_{0}\right]
\end{aligned}
$$

where $\sigma_{0}$ is $\sigma$ at $T_{0}$, A the effective $\mathrm{H}^{+}$concentration and B the Activation energy of $\mathrm{H}^{+}$. The estimated values of the apparent activation energy were $12 \mathrm{~kJ} / \mathrm{mol}$ for SDPNR-graft-PS and $17 \mathrm{~kJ} / \mathrm{mol}$ for Nafion $117^{\circledR}$, respectively. 
The value of the activation energy for SDPNR-graft-PS was less than that for Nafion $117^{\circledR}$ and it was quite lower than the reported value of the activation energy for sulfonated polystyrene, i.e. about $30 \mathrm{~kJ} / \mathrm{mol}$ [15]. From the results, we may consider that the proton-transport of SDPNR-graft-PS with nanomatrix channel and Nafion $117^{\circledR}$ occurs in a manner of Grotthuss mechanism, in which the proton-jump from one sulfonic acid to the other may takes place. In this case, we may compare the effective $\mathrm{H}+$ concentration between SDPNR-graft-PS and Nafion $117^{\circledR}$. In equation (9), $T_{0}$ of SDPNR-graft-PS may be assumed to be similar to that of Nafion $117^{\circledR}$, since SDPNR-graft-PS and Nafion $117^{\circledR}$ are floating in water in use. Furthermore, the slopes in Fig. 9 may be approximated to be similar to each other. Under these circumstances, thus, the gap between the proton conductivities of SDPNR-graft-PS and Nafion $117^{\circledR}$ are directly proportional to the difference in the effective $\mathrm{H}^{+}$ concentration estimated from intercept of the Arrhenius plot. The effective $\mathrm{H}^{+}$concentration of SDPNR-graft-PS was found to be about 10 times as high as that of Nafion $117^{\circledR}$, as shown in Fig. 9.

In table 2, the value of the proton conductivity of SDPNR-graft-PS was about 5 times as high as that of Nafion $117^{\circledR}$. It was about 10 times higher than the value of the proton conductivity of sulfonated PS, even though the amount of sulfonated PS contained in SDPNR-graft-PS was about 1/3, compared with sulfonated PS, itself. It is, consequently, rational to consider that the value of the proton conductivity of sulfonated PS present in SDPNR-graft-PS is 5 times as high as that of Nafion $117^{\circledR}$, when we assign the proton conductive path to sulfonated PS phase. The 5 times higher value of the proton conductivity may correspond to the 5 times higher effective $\mathrm{H}^{+}$concentration. This is consistent with the fact that a part of the ion clusters present in Nafion $117^{\circledR}$ are connected to each other to transport $\mathrm{H}^{+}$, but the others are not. Based on the results, it is possible to conclude that the nanomatrix channel of SDPNR-graft-PS plays an important role in the effective transport of the protons, by a factor of 5 .

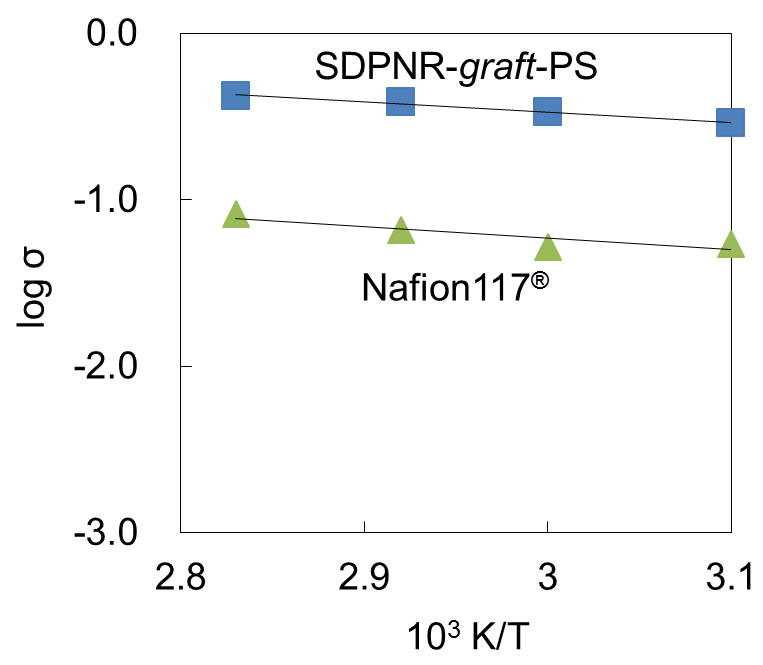

Fig. 9 Arrhenius plot for proton conductivity, $\sigma$, of SDPNR-graft-PS and Nafion $117^{\circledR}$

\section{Conclusion}

SDPNR--graft-PS was prepared by graft-copolymerization of styrene onto DPNR followed by the sulfonation using chlorosulfonic acid. The proton conductivity, IEC, sulfur content, and water uptake were 
9.8x10 $10^{-2} \mathrm{~S} / \mathrm{cm}, 1.41 \mathrm{meq} / \mathrm{g}, 10.2 \mathrm{w} / \mathrm{w} \%$, and $66.5 \mathrm{w} / \mathrm{w} \%$, respectively. TEM observation of the SDPNR-graft-PS revealed the formation of a continuous nanomatrix channel, which is effective to transport a lot of proton. The activation energy of SDPNR-graft-PS and Nafion117 was $12 \mathrm{~kJ} / \mathrm{mol}$ and $17 \mathrm{~kJ} / \mathrm{mol}$, respectively. The proton-transport in SDPNR-graft-PS with nanomatrix channel and nafion 117 was found to occur mainly via Grotthuss mechanism, since the activation energy of the membranes was less than $40 \mathrm{~kJ} / \mathrm{mol}$. The low value of the apparent activation energy and high value of the effective proton concentration for SDPNR-graft-PS demonstrated that the nanomatrix channel of SDPNR-graft-PS contributed to the effective transport of the protons.

\section{Acknowledgment}

This work was supported in part by a Grant-in-Aid (21655080) for Challenging Exploratory Research and Grant-in-Aid (223501000) for Scientific Research (B) from Japan Society for the Promotion of Science and JST-JICA SATREPS.

\section{References}

[1] W. Y. Hsu and T. D. Gierke, J. Membr. Sci., 13 (1983), 307.

[2] S. Kawahara, P. Suksawad, Y. Yamamoto, H. Kuroda, Macromolecules 42 (2009), 8557.

[3] P. Suksawad, K. Kosugi, Y. Yamamoto, K. Akabori, H. Kuroda, S. Kawahara, J. Appl. Polym. Sci., 122 (2011), 2403.

[4] X. Wu, K. Scott, Fuel Cells, 13 (2013), 1138.

[5] K. Jetsrisuparb, H. Ben youcef, A. Wokaun, L. Gubler, J. Membrane Sci., 450 (2014), 28.

[6] J. Fimrite, H. Struchtrup, N. J. Djilali, Electrochem. Soc., 2005, 152, 1804.

[7] K. Schmidt-Rohr, Q. Chen, Nature 2008, 7, 75.

[8] T. Sata, Ion Exchange Membranes, Preparation, Characterization, Modification and Application; The Royal Society of Chemistry: London, 2004.

[9] R. S. Yeo, Electrochem. Sci. Technol., 130 (1983), 533.

[10] S. Zhong, X. Cui, S. Dou, Y. Luo, W. Cui, S. Zhao, H. Zhu, W. Liu, Solid State Ionics, 181 (2010), 1499.

[11] M. Kato, T. Ito, Y. Aoyama, K. Sawa, T. Kaneko, N. Kawase, H. Jinnai, J. Polym. Sci.: Part B: Polym. Phys., 45 (2007), 677.

[12] S. Kawahara, Y. Yamamoto, S. Fujii, Y. Isono, K. Niihara, H. Jinnai, H. Nishioka, A. Takaoka, Macromolecules, 44 (2008), 4510.

[13] J. Kim, B. Kim, B. Jung, J. Membr. Sci., 207 (2002), 129.

[14] D. J. Patterson, J. L. Koenig, Makromol. Chem., 188 (1987), 2325.

[15] N. Carretta, V. Tricoli, F. Picchioni, J. Membr. Sci., 166 (2000), 189. 